\title{
Apresentação
}

\section{- Golpe de 1964: Reflexos, Desdobramentos e Olhares Cinquenta Anos Depois}

Jorge Christian Fernández*

$\mathrm{O}$ ano de 1964 mal havia se iniciado e, no seu horizonte, já se avistavam nuvens pouco alvissareiras. No ocaso de um mês de Março especialmente conturbado, um Golpe de Estado abalou a jovem república brasileira. Seus autores e mentores, militares e civis, representavam um vasto espectro das forças da direita no Brasil, desde os setores mais conservadores das forças armadas, da igreja e do latifúndio, até os grupos empresariais mais modernos e dinâmicos, da indústria, comércio ou mídia, frequentemente vinculados a interesses e capitais estrangeiros.

O Golpe, produto final de uma longa gestação conspiratória, mesmo que desordenada, e, cuja justificação era dada em termos de "defesa" da democracia contra o comunismo, foi desferido, paradoxalmente, contra um governo democraticamente eleito, mas cujo projeto econômico, político e social de cunho nacionalista, moderado e reformista não mais correspondiam aos anseios e interesses das elites dominantes.

\footnotetext{
* Doutor em História pela Universidade Federal do Rio Grande do Sul (UFRGS) e Professor de História da América do Curso de História (Campus Campo Grande/MS) da Universidade Federal de Mato Grosso do Sul (UFMS). intbrig@yahoo.com.br
} 
Mais do que isso, o Golpe no Brasil também sinalizava aos países vizinhos que os modelos de desenvolvimento pautados na participação do Estado na economia, na substituição de importações e baseados no pacto social se encontravam à beira do colapso. No particular contexto histórico da Guerra Fria, tais governos se encontraram assimetricamente imprensados: pelo alto, sob a agressiva investida dos imperialismos, especialmente o estadunidense, no marco de ascensão de um novo regime de acumulação integral de capital; e, pela base, com a radicalização dos movimentos sociais contestatários inspirados nas recentes experiências revolucionárias, anti-imperialistas e de libertação nacional do mundo periférico. E conviria destacar, em especial, o caso de Cuba que, destarte o seu reduzido espaço geográfico e limitado poder ofensivo real, foi superdimensionada como uma ameaça ao poderio econômico-militar de Washington em todo o continente por tornar-se um exemplo de ousadia e resistência frente aos Estados Unidos e, cuja experiência revolucionária poderia ser, em tese, emulada em qualquer país latino-americano, desde a fronteira do Rio Grande, ao norte, até os confins patagônicos.

Neste ano de 2014, completa-se exatamente cinquenta anos do Golpe de Estado de 31 de Março/01 de Abril de 1964. Os remanescentes e herdeiros ideológicos da ditadura ainda continuam a bradara desgastada cantilena de que o Golpe de 1964 foi uma "ação democrática" para "salvar o país" de uma pretensa ameaça do comunismo. Porém, tais acepções sobre o ocorrido em 1964 não recebem, nos dias de hoje, um eco similar ao que eles outrora receberam da sociedade em geral. Durante o seu longo período de duração, a ditadura brasileira (em especial) conseguiu forjar uma representação bastante positiva no imaginário social e político, apesar do emprego sistemático da violência institucional e das repetidas violações aos direitos humanos cometidos ao longo desses vinte e um anos (com intensidade variada, conforme necessidades conjunturais). Evidentemente que tal percepção "benévola" encontrava arraigo nos setores favorecidos com o regime, especialmente nas classes alta e média, mas não somente.

Apesar de suas particularidades nacionais, as Ditaduras de Segurança Nacional do Cone Sul utilizaram (em graus distintos) a lógica binária da 
"mão que bate é a mão que afaga" e empregaram o terror Estatal buscando combinar medo generalizado e terror pontual com recompensa material para ampliar uma base de apoio em determinados grupos sociais. Assim, os governos equacionaram o Terrorismo de Estado (simultaneamente seletivo e indiscriminado, o que the garante um efeito de irradiação social) com mecanismos de criação de consenso social. Consenso este que seria obtido, em parte, mediante concessões de benefícios materiais a setores da população. Mas, além disso, não podemos esquecer o peso exercido pela propaganda maciça exercida desde e para o Estado, por seus agentes, mas também por seus colaboradores (mídia, personalidades artísticas, lideranças civis, etc.), em combinação com instrumentos tais como a censura, a repressão, a desqualificação, a criminalização, a demonização e, em alguns casos, até o extermínio físico daqueles tidos como opositores mais perigosos.

A combinação e interação desses fatores não somente possibilitou a hegemonia do poder, como também delineou o nível de sucesso ou aceitação dos regimes ditatoriais do Cone Sul que aplicaram o terror de Estado, moldando o teor positivo ou negativo da sua imagem e garantindo a permanência desta construção tanto no plano subjetivo quanto na memória coletiva. Especificamente no caso brasileiro, não era incomum ouvirmos (e até ouvimos ainda!) em expressões orais e escritas do senso comum (ecoa até mesmo em meios acadêmicos), a percepção de que, apesar da violência, dos abusos e da corrupção da ditadura, o saldo do regime militar foi positi$v o$, seja porque possuía um projeto de desenvolvimento que deixou um "legado" ao país, ou porque teve um relativo sucesso em matéria econômica, ou porque havia mais "ordem e segurança"...

Em outras palavras, pode se dizer que, em determinados grupos sociais se exerceu (e se exerce ainda) uma clara relativização do emprego sistemático do terror, das arbitrariedades e dos crimes cometidos pela ditadura, e nessa relativização (que ora beira a banalização, de tão grosseira), que se traduz em um mero "balanço" entre os crimes e as benesses do regime, os segundos terminam geralmente ofuscando os primeiros, de modo a gerar uma hierarquização um tanto inversa. Aqui no Brasil, o terror e o 
"milagre econômico" foram instrumentos de dominação e cooptação, em tese opostos, mas utilizados de modo complementar. Todavia, ao contrário de outros países vizinhos, o terror foi administrado de forma mais especifica e aplicado com precisão quase cirúrgica, principalmente se comparado com a extensão e a profundidade do terror estatal aplicado na Argentina.

Ao contrário da ditadura argentina, a ditadura brasileira soube focalizar precisamente na sua mira os sujeitos considerados alvos da repressão e, assim, direcionar verticalmente a aplicação dos mecanismos do terror. Entretanto, esse caráter pontual da violência repressiva no Brasil não significa que o regime tenha sido "brando", se comparado aos outros regimes ditatoriais e, por extensão, "melhor" que eles. Se a ditadura brasileira torturou, assassinou e ocultou os cadáveres de seus oponentes em menor proporção do que a ditadura vizinha foi porque considerou que não havia necessidade concreta de fazê-lo em grande escala.

Assim sendo, independente das comparações "estatísticas" de contagem de mortos e/ou desaparecidos que possam ser efetuadas entre as ditaduras de Segurança Nacional para medir um suposto grau de brutalidade de tal ou qual regime, o que deve ser observado, em tais regimes, são características estruturais, tais como a sistematização e aplicação da tortura em grande escala, a racionalidade da repressão, a metodologia "científica" do terror, suas justificativas políticas e o arcabouço ideológico empregado foram muito similares em todas as ditaduras do Cone Sul.

Passados cinquenta anos, não se pode negar que o nosso país (em similar sintonia com o nosso subcontinente) passou por consideráveis mudanças históricas e que estas contribuíram para modificar a percepção da atual sociedade brasileira sobre aqueles tempos passados. No plano político-institucional, e especialmente nos últimos anos, com a assunção de governos mais identificados com as questões sociais e historicamente vinculados àqueles setores progressistas ou de esquerda e que participaram ativamente do polarizado cenário político dos anos 1960 e 1970 se reacendeu o debate sobre o incômodo passado recente, um debate postergado e ofuscado no imediato pós-ditadura. Em novembro de 2011, foi criada a Comissão Nacional da 
Verdade $(\mathrm{CNV})^{1}$, após anos de embates políticos entre militares e civis para definir alcances e limites de atuação que essa Comissão teria. Tal iniciativa, mesmo que tardia, exemplifica esse olhar atual do Poder Executivo com relação a medidas vinculadas à questão da memória e a busca da verdade histórica, em nome de uma reconciliação nacional efetiva.

No entanto, em função da condenação do Brasil na Corte Interamericana de Direitos Humanos (CIDH), no final de 2010, as ações do Estado brasileiro nesse sentido deveriam ser mais aprofundadas. No entendimento da CIDH, não basta apenas à criação da CNV ou facilitar o acesso à documentação repressiva pelas vítimas, seus familiares e também a pesquisadores em busca de informação antes proibida. O que é fundamental é que o Estado brasileiro remova todos os obstáculos jurídicos para poder "conduzir eficazmente a investigação penal dos fatos do presente caso, a fim de esclarecê-los, determinar as correspondentes responsabilidades penais e aplicar efetivamente as sanções e consequências que a lei disponha" ${ }^{2}$.E isto significa, segundo especialistas da área jurídica, começar pela anulação da Lei de Anistia de $1979^{3}$.

Cabe recordar que, ao longo da década de 1980, o Estado brasileiro advindo "democrático" procurou colocar uma "pedra" sobre os crimes da ditadura. Certamente que a assimétrica Lei de Anistia, duramente negociada entre a ditadura (ainda na posse das rédeas do poder) e alguns setores da "elite" da oposição, no marco de um progressivo descontentamento geral da população com o regime (especialmente após evidenciar os limites do "milagre") não deixava margem de manobra para tais discussões, o que redundou em "perdão incondicional" aos agentes da repressão e uma incontestável vitória dos setores da "linha dura" militar, que permaneceram impunes.

\footnotetext{
${ }^{1}$ Lei 12.528/2011. A CNV iniciou os seus trabalhos emmaio de 2012.

${ }^{2}$ CIDH, Caso Gomes Lund e outros (“Guerrilha do Araguaia”) Vs. Brasil, Exceções Preliminares, Mérito, Reparações e Custas, sentença de 24 de novembro de 2010, Série C, $n^{\circ}$ 219, parágrafo 256. Citado por GOMES, Luis F. disponível em: http://www.conjur.com. br/2011-mar-10/coluna-lfg-lei-anistia-viola-convencoes-direitos-humanos
}

${ }^{3}$ Lei no 6.683 , de 28 de agosto de 1979 . 
Por outro lado, deve se apontar que, sob a justificativa de não atravancar o processo de transição para um Estado democrático de direito, os governos civis evitaram enfrentar o poderio militar, bem como tocar no problema da sujeição das Forças Armadas às regras do jogo democrático. Por fim, não se pode obliterar que parte considerável da elite (em especial os políticos e empresários) e da classe média brasileira era também comprometida, direta ou indiretamente, e em maior ou menor grau, com o regime ditatorial pregresso, o que explicaria seu interesse em "esquecer" determinadas ações e alianças do passado que não lhe seriam adequadas nem favoráveis naquele ambiente de devir "democrático". Nesse sentido, a "amnésia histórica" converteu-se em prática oportuna e corrente de distintos setores sociais.

Nos dias atuais, é possível evidenciar que o Estado brasileiro, pelo menos na figura do poder executivo, efetuou "um passo a frente" no sentido de responder às históricas demandas pelo direito à memória e à verdade. Mas, haverá por parte das outras instâncias do Estado um "segundo passo"? Isto é, como enfrentar a demanda por justiça? Esta questão primordial ainda carece de resposta efetiva. O poder judiciário, até o momento, tem recuado diante desta problemática, especialmente no que tange a revisão da Lei de Anistia, pois o Superior Tribunal Federal continua a ratificá-la, à revelia de instância jurídica internacional e em claro desrespeito aos Tratados Internacionais de Direitos Humanos dos quais o Brasil é signatário.

Neste sentido, porém, a demanda por justiça tem lugar na pauta da atual agenda das novas gerações que participam dos movimentos sociais. Se durante décadas as reclamações pelos crimes da ditadura se restringiram a círculos de vítimas e seus familiares, ex-presos políticos, militantes ou a organizações de direitos humanos, esta questão agora transcende este núcleo inicial, impregnando e polarizando o debate nos distintos âmbitos do tecido social. E neste contexto favorável à memória, não estranhamente, surgem as outrora silenciadas "memórias subterrâneas" dos sobreviventes desse passado traumático e que hoje encontram eco, tanto com a juventude, interessada em conhecer um passado que thes foi "negado", quanto com 
os historiadores (e outros pesquisadores das áreas humanas) interessados em produzir conhecimento sobre esses temas em meio a esse processo de emergência de antigas questões e revalorização das experiências daquele tempo passado. Ou seja, preocupados em compreender por que esse passado não elaborado "teima em passar", aflorando em determinados contextos e nos relembrando permanentemente da sua vigência.

Ao encontro deste momento histórico tão significativo, a Revista Albuquerque dedica este Número 11 a temática das Ditaduras de Segurança Nacional no Brasil e Cone Sul, com o Dossiê intitulado: O Golpe de 1964: Reflexos, Desdobramentos e Olhares Cinquenta Anos Depois. Embora inicialmente focado na experiência ditatorial brasileira, em virtude da data a ser rememorada, este Dossiê pretende abordar a temática desde uma perspectivamais abrangente. Não somente em termos de expressar a diversidade de olhares e enfoques possíveis sobre as ditaduras partindo de prismas teóricos e metodológicos distintos. Mas especialmente em termos de ampliar o recorte geográfico ao incluir pesquisas históricas sobre/ou os "nossos vizinhos" da região, por entender que existem interconexões, elementos em comum que, independente de particularidades, vinculam as distintas experiências ditatoriais do Cone Sul entre as décadas de 1960 e 1980.

O presente Dossiê inicia com o texto de Carlos Artur Gallo "Comissões da Verdade em Perspectiva: notas sobre a experiência uruguaia, chilena e argentina", em que o autor, após historicizar sobre o período autoritário na Argentina (1976-1983), no Chile (1973-1990) e no Uruguai (1973-1985) nos estabelece, em escala comparativa, uma análise concisa sobre as distintas formas que os países do Cone Sul enfrentaram a problemática que encerra a trinômia memória, verdade e justiça, nos seus respectivos processos de democratização, na tentativa de fazer face aos problemas do "legado" do passado ditatorial.

O artigo de Jefferson Gomes Nogueira, "História, imprensa e a construção da realidade durante o regime militar no Brasil (1964/1985)", aproxima-nos mediante o estudo da produção histórica sobre a imprensa e o regime militar no Brasil, dos mecanismos e agentes utilizados (censura, 
propaganda, censores, jornalistas, etc.) tanto pelo aparato estatal repressor, quanto pelos seus colaboradores privados para construir uma "realidade" parcial e conveniente que lhe possibilitasse atingir a hegemonia e o controle social pretendido.

Desde uma perspectiva estadual, Cristina Medianeira Ávila Dias, discorre sobre "O terrorismo de Estado (TDE) no Rio Grande do Sul: perseguição, prisãoe tortura de militantes da Vanguarda Popular Revolucionária (VPR)", utilizando como ponto de partida, o surgimento de um grupo armado de esquerda, no extremo sul do Brasil, e estabelecendo a relação deste com o desenvolvimento e a consolidação da estrutura repressiva montada pelos órgãos de segurança para combater as atividades das forças que resistiam ao regime, bem como aborda a metodologia empregada pelo aparato repressivo.

Já Enrique Serra Padrós nos apresenta, em seu artigo, uma reflexão sobre um tema delicado e pouco abordado, aqui no Brasil em particular: "A guerra contra as crianças: práticas de sequestro, desaparecimento e apropriação de identidade no século XX". Nesse artigo, focaliza as experiências do sequestro de crianças durante as ditaduras de Segurança Nacional da Argentina e do Uruguai, ocorridas entre as décadas de 1970 e 1980, uma das mais brutais práticas do Terrorismo de Estado platino inserido na lógica da captura do "butim de guerra" e vinculado aos projetos de "refundação" social trazidas no bojo ideológico de tais ditaduras. Além disso, Padrós contextualiza e estabelece uma relação desta prática criminosacom outras experiências correlatas (na Europa ocupada pelo nazismo, na Espanha de Franco e nos recentes conflitos armados da África), no transcorrer do século XX e início do XXI, apontando a persistência destes mecanismos de opressão social, os profundos traumaspor eles gerados e como tais crimes se projetam ao longo do tempo, incidindo sobre diversas gerações.

O artigo de Ananda Simões Fernandes e Silvia Simões, “Apontamentos acerca da conexão repressiva entre as ditadurasbrasileira e chilena", perscruta a multifacetada e complexa rede de conexão repressiva entre as ditaduras brasileira e chilena, chancelada após a vitória do golpe de Estado chi- 
leno, em 11 de setembro de 1973. A pesquisa das autoras, baseada em fontes primárias, centra sua análise na atuação combinada de organismos brasileiros e chilenos nos mais diversos âmbitos (policiais, diplomáticos, etc.) em sua colaboração na luta contra a "subversão", e como essa conexão se consolidou em direção à formalização de uma rede orgânica e transnacional de repressão extraterritorial, que envolveria o conjunto das ditaduras do Cone Sul, e que passaria para a história da região comoa “Operação Condor”.

A autora Caroline Silveira Bauer, no texto "Um passado que não passa: a persistência do crime de tortura na democracia brasileira", disseca uma das ferramentas mais amplas e intensamente utilizadas pelo Estado terrorista brasileiro, a tortura. No entanto, o trabalho não se restringe sua análise ao período ditatorial somente, pois a autora excede os limites temporais da ditadura e incursiona sobre a permanência de tal prática abjeta até os dias de hoje. Um tema que nos leva a refletir duplamente. Por um lado, sobre as continuidades das práticas dos regimes ditatoriais sob o manto democrático e, por outro, sobre o próprio caráter e o alcance da nossa democracia.

Seguindo na dinâmica dos processos de transição das ditaduras para os regimes democráticos, Claudia Wasserman nos apresenta "Democracia e ditadura no Brasil e na Argentina: o papel dos Intelectuais". A autora, cuja densa narrativa nos transporta até a década de 1980, foca seu olhar nos intelectuais brasileiros e argentinos, comparando e analisando o papel representado por estes, enquanto sujeitos políticos, sociais e históricos, no contexto da chamada redemocratização. Um período promissor em termos de efervescência social e cultural permeado pela retomada da discussão política e pela possibilidade de retorno daqueles que haviam padecido o exílio; mas que também foi uma era impregnada pela "cultura do medo", pela desconfiança mútua entre os que haviam permanecido e aqueles que haviam partido ou obrigados a partir, bem como profundamente marcada pelas então recentes cicatrizes provocadas pelas experiências autoritárias.

Mario Hugo Ayala, em "Los exiliados argentinos en Venezuela ante el inicio de latransición a la democracia en la Argentina", também efetua seu recorte temporal no período da transição, porém, desde outra inter- 
-relação geográfica e transnacional: Argentina e Venezuela. Ele aborda especificamente o fenômeno do exílio dos argentinos (um dos mais numerosos exílios da região) perante às questões surgidas com a volta da democracia e os dilemas que esta apresentava, por exemplo, a possibilidade do regresso ao país, mas também o leque de problemas políticos, grupais e subjetivos que o "retorno" (ou desexilio) paradoxalmente gerava. O artigo de Ayala está embasado em ampla documentação, utilizando-se de testemunhos publicados e, principalmente, de materiais inéditos oriundos de fontes orais.

Encerra o nosso Dossiê a obra de Monica Piccolo Almeida, "Agentes e Agências no Ocaso da Ditadura Empresarial Militar e a Reedição do "Milagre'". Nesse texto, a autora propôs-se a analisar as diretrizes que guiaram a política econômica da ditadura brasileira em sua derradeira etapa, o governo de João B. Figueiredo, utilizando como hipótese central que os intentos aplicados em matéria de política econômica pretendiam recuperar os níveis de crescimento da década anterior, buscando o ressurgimento do "milagre econômico". No entanto, tais tentativas estiveram perpassadas por contradições inerentes ao próprio sistema capitalista e pelas formas que este adquiriu nas regiões periféricas e dependentes, bem como por disputas, em virtude de interesses diversos, dentre os grupos da classe dominante mediante a ação de agentes específicos, públicos e privados, inseridos diretamente ou não no seio do aparato estatal.

Desse modo, e seguindo uma perspectiva acadêmica plural e democrática, bem representada por esta diversidade e riqueza temática, assim como pelas distintas aproximações e análises do passado apresentadas pelos autores neste Dossiê (cada um partindo de abordagens teóricas e metodológicas diferenciadas), procuramos contribuir com a reflexão crítica e o debate histórico sobre o nosso passado recente e compartilhado aqui na região sul da América do Sul, promovendo o avanço do saber (dentro e fora da academia), bem como da produção historiográfica. Esperamos que o resultado final, este Dossiê Número 11 da Revista Albuquerque, agrade aos nossos leitores exigentes. 